\section{PS-270 BREASTFEEDING SUPPORT IN SPANISH NICUS AND THE BABY-FRIENDLY HOSPITAL INITIATIVE: A NATIONAL SURVEY}

C Alonso Diaz, MI Utrera- Torres, C Alba-Romero, B Flores- Anton, D Escuder-Vieco, CR Pallas- Alonso. Neonatology, !2 de Octubre Hospital. SAMID Network, Madrid, Spain

\subsection{6/archdischild-2014-307384.570}

Background The Baby-Friendly Hospital Initiative (BFHI) has a positive effect on breastfeeding but there are few studies examining this association in NICUs.

Aim To compare breastfeeding support in Spanish NICUs at hospitals with any BFHI stage or full accreditation (Group1) with NICUs of hospitals that haven't begun this initiative (Group2).

Methods Validated questionnaire of breastfeeding support (85 questions) were distributed to head doctors of level II and III public Spanish NICUs $(\mathrm{N}=142)$, from November 2013 to March 2014.

Results The response rate was 90\%. Seven NICUs were in designated Baby-friendly hospitals and 44 were in some accreditation stage. These 51 NICUs (Group1) had implemented a higher number of breastfeeding support measures with significant differences in the steps 1, 2, 4, 5 and 8 of the NICU BFHI ten steps. The most important results are in Table 1.

\begin{tabular}{llll} 
Abstract PS-270 Table 1 & & & \\
\hline Breastfeeding support measures & Group1 & Group2 & $\mathbf{p}$ \\
Systematic breastfeeding training for staff & $35 / 51(68 \%)$ & $33 / 78(42 \%)$ & 0.003 \\
Identified person responsible for breastfeeding & $37 / 51(72 \%)$ & $33 / 78(42 \%)$ & 0.0007 \\
Written breastfeeding information to parents & $47 / 51(92 \%)$ & $58 / 78(74 \%)$ & 0.01 \\
Breastfeeding classes for parents & $21 / 51(41 \%)$ & $19 / 78(24 \%)$ & 0.04 \\
Mothers advised to start pumping before $6 \mathrm{~h}$ & & & \\
after birth & $36 / 51(70 \%)$ & $42 / 78(53 \%)$ & 0.057 \\
Early first kangaroo care & $36 / 42(85 \%)$ & $40 / 66(60 \%)$ & 0.01 \\
Encourage demand breastfeeding & $30 / 51(58 \%)$ & $19 / 78(24 \%)$ & $<0,0001$ \\
Semi-demand feeding as a transitional strategy & $31 / 51(60 \%)$ & $21 / 78(26 \%)$ & 0.0001 \\
Use of pacifier changed during breastfeeding & & & \\
transition & $26 / 51(50 \%)$ & $25 / 78(32 \%)$ & 0.03 \\
\hline
\end{tabular}

Conclusions Being in the BFHI way in the Maternity Unit improves the implementation of practices to promote and support breastfeeding in NICU.

\section{PS-271 CYTOKINE CONTENT OF HUMAN MILK AND ATOPIC DERMATITIS IN BREASTFED INFANTS}

${ }^{1} \mathrm{NM}$ Díaz-Gómez, ${ }^{2} \mathrm{E}$ Domenech, ${ }^{3} \mathrm{M}$ Murray, ${ }^{4}$ I González, ${ }^{4} \mathrm{~J}$ De Castro, ${ }^{4} \mathrm{C}$ Vázquez, ${ }^{5} \mathrm{D}$ Escuder. 'Nursing, University of La Laguna, La Laguna, Spain; ${ }^{2}$ Paediatric, Hospital Universitario de Canarias (University of La Laguna), La Laguna, Spain; ${ }^{3}$ Paediatric, Hospital Universitario de Canarias, La Laguna, Spain; ${ }^{4}$ Laboratory, Hospital Universitario Nuestra Señora de Candelaria, Santa Cruz de Tenerife, Spain; ${ }^{5}$ Human Milk Bank, Hospital Universitario 12 de Octubre, Madrid, Spain

\subsection{6/archdischild-2014-307384.571}

Background The protective effect of breastfeeding has been linked to immunomodulating agents in human milk, including cytokines.

Objective To evaluate the possible relationship between human milk cytokine content and atopic dermatitis in breastfed term infants.
Material and methods In 114 samples of milk fed to term infants, IL- $1 \beta$, IL-2, IL-4, IL-5, IL-10, IFN $\gamma, T G F-\beta 1$ and TNF content were determined by flow cytometry. Breastfeeding duration and diagnosis of atopic dermatitis were telephonically recorded at 18 months.

Results Atopic dermatitis appeared in 24 infants (21\%). No allergies were recorded in $89(78 \%)$. We found no significant differences in maternal age $(34.8 \pm 2.7$ vs $34.7 \pm 3.6$ years $)$, maternal allergies (54\% vs 46\%), birth-weight (3288 \pm 512 vs $3270 \pm 586 \mathrm{~g})$ or breastfeeding duration $(5.7 \pm 1.2$ vs $5.6 \pm$ 1.4 months). Cytokines studied were detected in the following samples of mature milk: IL-1 $\beta$ 25\%, IL-2 42\%, IL-4 23\%, IL-5 17\%, IL-10 28\%, IFN $\gamma$ 25\%, TGF- $\beta 1$ 16\% and TNF $18 \%$. In milk fed to infants with atopic dermatitis, mean concentration of TGF- $\beta 1$ was higher $(428 \pm 221$ vs $282 \pm 222 \mathrm{pg} / \mathrm{ml})$, while that of IL- $1 \beta(2.2 \pm 1.1$ vs $3.6 \pm 7.5 \mathrm{pg} / \mathrm{ml}), \mathrm{IL}-2(6.7 \pm 3.3$ vs $9.6 \pm 6.8 \mathrm{pg} / \mathrm{ml}), \mathrm{IL}-4(2.0 \pm 0.7$ vs $4.0 \pm 5.2 \mathrm{pg} / \mathrm{ml}), \mathrm{IL}-5(0.6$ \pm 0.3 vs $1.2 \pm 0.9 \mathrm{pg} / \mathrm{ml})$, IL-10 (1.8 \pm 0.7 vs $3.8 \pm 3.1 \mathrm{pg} /$ $\mathrm{ml}), \operatorname{IFN} \gamma(2.9 \pm 4.2$ vs $5.9 \pm 9.1 \mathrm{pg} / \mathrm{ml})$ and TNF $(2.2 \pm 05$ vs $5.4 \pm 7.1 \mathrm{pg} / \mathrm{ml}$ ) was lower, although differences were only significant for IL-10 ( $\mathrm{p}=0.02)$.

Conclusions The results suggest a possible relationship between human milk IL-10 content and atopic dermatitis in infants. However, wide variability in cytokine concentration means the sample size must be increased to draw definitive conclusions.

\section{PS-272 EARLY NUTRITION AND POSTNATAL GROWTH AND THE RISK OF RETINOPATHY OF PREMATURITY (ROP)IN VERY PRETERM INFANTS (VPI)}

M Izquierdo, M Minguez, A Martinez Monseny, I Iglesias-Platas. Neonatology, Hospital Sant Joan de Deu, Esplugues Llobregat, Spain

\subsection{6/archdischild-2014-307384.572}

Background Retinopathy of prematurity (ROP) is the main cause of visual impairment in very preterm infants (VPI). Several factors contribute to the development of ROP; recently, the relationship between severe grades of ROP and poor early weight gain and nutrition has been investigated. Aim: Evaluation of nutritional supply during the first week of life and in-hospital postnatal growth of very preterm children with and without ROP.

Methods Retrospective study of clinical data from a cohort of VPI ( $\leq 32$ GA) screened for ROP from 2002-2013 in a tertiary NICU. Collection of information regarding birth weight, postnatal growth, nutritional data and clinical course. ROP was classified according to international guidelines.

Results Of 473 VPI screened, 165 (34,9\%) patients developed some degree of ROP; 30 needed treatment with laser therapy. Babies with any degree of ROP and those with severe ROP were of lower gestational age and had a more complicated clinical course. Regarding growth, there were no differences in initial weight loss and recovery or enteral nutrition during the first week. In spite of higher parenteral nutritional supply (1st week), babies who developed ROP had a lower relative daily weight gain between birth and 28 days of life (dol) and deviated from expected intrauterine growth significantly more. This pattern persisted at 36 weeks and at discharge.

Conclusions VPI who develop ROP display stunted growth when compared to non-ROP counterparts. This is in spite of a higher parenteral nutritional supply during the first week of life. Further analysis of nutritional data is under course. 